\title{
APAGAMENTO DE /R/ EM CODA SILÁBICA NA VARIEDADE DO INTERIOR PAULISTA
}

\author{
CODA /R/ DELETION IN THE COUNTRYSIDE OF SÃO PAULO STATE
}

\author{
Márcia Cristina do Carmo ${ }^{1}$ \\ Isabela Ribeiro Taborda ${ }^{2}$
}

RESUMO: Este trabalho analisa o apagamento variável de / R/ em contexto de coda silábica em posição medial e final de vocábulo no interior paulista. Como arcabouço teórico, utilizamo-nos da Teoria da Variação e Mudança Linguística, também denominada Sociolinguística Quantitativa (LABOV, 2008 [1972]). Durante a pesquisa, foram analisados oito inquéritos de fala espontânea retirados do banco de dados IBORUNA (IBILCE/UNESP - FAPESP 03/08058-6). A partir da análise estatística realizada pelo programa Goldvarb X, foram obtidos 2400 dados, dos quais $52,2 \%$ sofreram o processo. Constatamos que o fenômeno de apagamento ocorre motivado por variáveis linguísticas, como classe morfológica da palavra e posição da sílaba, em detrimento de variáveis sociais, como faixa etária e escolaridade. Notamos que, quando se trata de verbos em posição final de vocábulo, como em falar e estudar, o /R/ em coda costuma ser cancelado, como em falá $\varnothing$ e estudáØ. Finalmente, devido à irrelevância da faixa etária para a aplicação do processo, podemos afirmar que o apagamento de / $\mathrm{R} /$ trata-se de um processo em variação estável na variedade analisada.

Palavras-chave: Teoria e análise linguística; Sociolinguística; Variação morfofonológica; Apagamento do / $\mathrm{R} /$ em coda silábica.

ABSTRACT: This research analyzes /R/-deletion in syllable coda in medial and final contexts in the countryside of São Paulo State. As the theoretical framework, we follow the Linguistic Variation and Change Theory, also known as Quantitative Sociolinguistics (LABOV, 2008 [1972]). During this research, eight interviews with spontaneous speech samples taken from the IBORUNA database (IBILCE/UNESP - FAPESP 03/08058-6) were analyzed. According to the statistical analysis, with the utilization of Goldvarb X, 2400 occurrences were found, from which $52.2 \%$ were deleted. It is observed that / R/-deletion is motivated by linguistic variables, as morphological class and syllable position, and not by social variables, as age group and level of education. It is evinced that when there is a verb with / R/ in final position, e.g. falar ('to speak') and estudar ('to study'), the final /R/ is generally deleted, e.g. falá $\varnothing$ and estudá $\varnothing$. Finally, due to the irrelevance of age group to the application of the process, we can infer that $\mathrm{R}$-deletion is in stable variation in the analysed variety.

Keywords: Linguistic Theory and Analysis; Sociolinguistics; Morphophonological Variation; /R/-deletion in Syllable Coda.

\section{Introdução}

Neste trabalho, analisamos o apagamento variável de / R/ em coda silábica em contexto de meio e de fim de vocábulo na variedade do interior paulista, como em informação infoØmação e

\footnotetext{
${ }^{1}$ Docente adjunta vinculada ao Departamento de Estudos da Linguagem (DEEL) da Universidade Estadual de Ponta Grossa (UEPG). Doutora em Estudos Linguísticos pela Universidade Estadual Paulista (UNESP/IBILCE). Realizou Pós-Doutorado na University College London (UCL/Reino Unido). E-mail: mccarmo@uepg.br

2 Mestranda em Estudos da Linguagem pela Universidade Estadual de Ponta Grossa (PPGEL/UEPG). Licenciada em Letras - Português/Inglês (UEPG). E-mail: isabela.taborda05@gmail.com
} 
jogador $\sim$ jogadôØ, respectivamente. A hipótese inicial que norteou o presente trabalho era a de que o apagamento de / R/ em coda silábica ocorreria principalmente em verbos, como em vendêØ (para vender ), e com menor frequência em nomes, como em armário, por exemplo. Para a descrição desse fenômeno, embasamo-nos no arcabouço teórico da Teoria da Variação e Mudança Linguística, proposta por William Labov (2008 [1972]). Além disso, pautamo-nos nos estudos de Bagno (2015), Oushiro e Mendes (2014), Tarallo (2003), entre outros, sobre a aplicação do processo em outros falares do Português Brasileiro (doravante, $\mathrm{PB})$.

A investigação do presente trabalho conta com amostras de fala do banco de dados IBORUNA, resultado do Projeto Amostra Linguística do Interior Paulista (ALIP - GONÇALVES, 2007), conduzido na Universidade Estadual Paulista (UNESP/IBILCE) na região do município de São José do Rio Preto (SP) e financiado pela Fundação de Amparo à Pesquisa do Estado de São Paulo (FAPESP - Proc. 03/08058-6). Desse banco de dados, analisamos oito entrevistas compostas por amostras de fala espontânea, sendo selecionadas variáveis independentes linguísticas e extralinguísticas para a análise dos dados.

A maioria das pesquisas já realizadas a partir do banco de dados mencionado discorre sobre vogais (SILVEIRA, 2008; CARMO, 2009; 2013; 2014; 2019; CARMO; TENANI, 2013), e não consoantes. Nesse sentido, o presente trabalho contribui para o preenchimento de uma lacuna em relação à descrição e análise da variação linguística no interior paulista e, de forma mais abrangente, no PB.

O presente artigo está organizado da seguinte forma: na seção 1, encontra-se a Fundamentação Teórica do presente trabalho; em 2, são apresentados os Materiais e Métodos empregados; na seção 3, são feitas a Análise e a Discussão dos Dados, seguidas pelas Considerações Finais e Referências.

\section{Fundamentação teórica}

Concebendo a língua como heterogênea (LABOV, 2008 [1972]; TARALLO, 2003), este trabalho objetiva compreender, analisar e descrever o apagamento de / $R /$ em coda silábica no interior paulista. Com base na Teoria da Variação e Mudança Linguística (LABOV, 2008 [1972]) e contando principalmente com os trabalhos de Bagno (2015), Chagas (2017), Guy e Zilles (2007), Labov (2008 [1972]), Oushiro e Mendes (2014) e Tarallo (2003), visamos investigar quais rumos a variável perpassa na comunidade de fala investigada. Nesta seção, serão apresentados dois subtópicos que nos auxiliarão a esclarecer alguns conceitos fundamentais para a análise e discussão dos dados levantados. São eles: 1.1 Teoria da Variaģão e Mudança Linguística; e 1.2 Apagamento variável de /R/ em coda silábica.

\subsection{Teoria da variação e mudança linguística}

A Teoria da Variação e Mudança Linguística (LABOV, 2008 [1972]), também denominada Sociolinguística Variacionista, concebe a língua como um sistema heterogêneo e social. O grande precursor da Teoria da Variação e Mudança Linguística é o estadunidense William Labov, com sua obra mais expressiva: Padrões Sociolinguísticos (Sociolinguistic Patterns, 2008 [1972]). Nesse livro, Labov discorre, dentre outros tópicos, sobre a estratificação social do /R/ em lojas de departamentos na cidade de Nova Iorque. A princípio, o autor tinha como hipótese de pesquisa que, em três lojas diferentes em Nova Iorque, os vendedores utilizavam duas formas linguísticas distintas no que se refere ao /R/ pós-vocálico da língua inglesa. Essas variantes correspondiam à presença ou à ausência do / R/ na pronúncia de palavras como: car ('carro'), card ('cartão') e fourth 
('quarto). Para o autor, as pronúncias diferentes para a mesma resposta ${ }^{3}$ seriam motivadas pela classe social dos clientes da loja. A hipótese previa, ainda, que a realização do /R/ pós-vocálico seria mais frequente por funcionários da loja de status mais alto, diminuindo o uso da variante em questão quanto menor o status da loja. Suas hipóteses foram confirmadas, pois, na loja em que os clientes eram mais abastados socioeconomicamente (Saks Fifth Avenue), 62\% dos informantes realizaram foneticamente o /R/ pós-vocálico; na loja que atendia o público de classe média (Macy's), 51\% utilizaram a variante mencionada; e, na loja frequentada por público de classe socioeconômica baixa (S. Klein), o resultado foi de que apenas $21 \%$ pronunciaram o / R/ em posição pós-vocálica.

$\mathrm{Na}$ teoria sociolinguística proposta pelo autor, uma variável pode ser compreendida como um conjunto de formas linguísticas em variação. Nesse conjunto, temos as variantes, compreendidas como as "[...] diversas maneiras de dizer a mesma coisa em um mesmo contexto, e com o mesmo valor de verdade" (TARALLO, 2003, p. 8). Como exemplo, temos o apagamento de /R/ em contexto de coda silábica no PB - objeto de estudo deste trabalho. Para esse conjunto de formas linguísticas em variação, têm-se duas variantes: a presença e a ausência da consoante na forma de superfície. ${ }^{4} \mathrm{Ou}$ seja, em palavras como jogar, a pronúncia de /R/ pode ser mantida (e pronunciada com um retroflexo) ou pode ser apagada.

Após a explicação dos conceitos de variável e variantes linguísticas, visamos, agora, esclarecer os conceitos de variante padrão/não-padrão, conservadora/inovadora e de prestígio/estigmatizada. A variante considerada padrão, conservadora e prestigiada em um dialeto costuma ser utilizada por uma comunidade de fala que goza de prestígio social e teve acesso a uma alta escolarização. Essas características (variante-padrão, conservadora e prestigiada socialmente) são postas juntas, pois "em geral, a variante considerada padrão é, ao mesmo tempo, conservadora e aquela que goza do prestígio sociolinguístico na comunidade" (TARALLO, 2003, p. 12). A variante não-padrão, por outro lado, geralmente é utilizada por sujeitos que vivem à margem da sociedade. Nesse sentido, ela seria, ao mesmo tempo, não-padrão, inovadora e estigmatizada socialmente. Por meio da investigação de determinadas variáveis extralinguísticas neste trabalho, como sexo/gênero e escolaridade (apresentadas mais detalhadamente na seção 2.2), poderão ser obtidos eventuais indícios de estigma ou prestígio social para cada variante analisada.

Outra variável extralinguística analisada na presente investigação é a faixa etária, necessária para a análise do status da mudança linguística em tempo aparente. De acordo com Paiva e Duarte (2015), o estudo da mudança pode ser realizado em tempo real ou em tempo aparente. No primeiro caso, há um recorte diacrônico de tempo, por meio do qual os falantes são acompanhados pelo pesquisador periodicamente; assim, o realizador da pesquisa pode afirmar o que ocorreu com o fenômeno analisado, uma vez que acompanhou a ocorrência do processo em uma determinada comunidade de fala por um período temporal, geralmente correspondente a 20 anos (tempo real de curta duração). Nessa mesma perspectiva, também há a possibilidade de se fazer um estudo a partir de textos escritos, que perpasse as fronteiras seculares na análise de um fenômeno, a fim de traçar os caminhos pelos quais uma variável passou para chegar ao estado em que se encontra atualmente (tempo real de longa duração).

A pesquisa realizada em tempo aparente, como a realizada nesta investigação, consiste em um recorte sincrônico de amostra de fala (PAIVA; DUARTE, 2015), não realizando comparações entre dados do mesmo informante com recortes passados e/ou futuros. Como o nome pressupõe, não há um acompanhamento periódico realizado como em uma pesquisa de tempo

\footnotetext{
3 Tendo em vista que o autor direcionava, ao seu interlocutor, questões que motivavam a realização de vocábulos que apresentavam / R/ em coda silábica.

${ }^{4}$ Por motivos de natureza tipográfica, no presente artigo, a ausência do /R/ será representada pelo símbolo " $\varnothing$ ", como em paráØ, enquanto sua realização fonética será marcada ortograficamente, como em parar. Deve-se destacar, no entanto, que a forma fonética presente no interior paulista para / R/ em coda silábica corresponde à consoante retroflexa.
} 
real. De modo geral, a pesquisa em tempo aparente é realizada por meio da consideração de faixas etárias distintas, como efetuado no presente trabalho. Feita essa breve exposição dos pressupostos teóricos da Teoria da Variação e Mudança Linguística (LABOV, 2008 [1972]), passamos à apresentação do processo investigado nesta pesquisa.

\subsection{Apagamento variável de / $R /$ em coda silábica}

Segundo Silva (2011), é em contexto de bordas de palavras ou encontros consonantais que o apagamento costuma ocorrer. Segundo a autora, o apagamento corresponde ao cancelamento de um segmento consonantal ou vocálico, também denominado cancelamento ou queda.

Como já citado anteriormente, este trabalho trata da análise do apagamento de $/ \mathrm{R} / \mathrm{em}$ contexto de coda silábica, ou seja, em fim de sílaba travada. Este fenômeno se faz presente, por exemplo, em palavras como tratar $\sim$ tratá $\varnothing$, conversa $\sim$ convé $\varnothing$ sa, em que o(a) informante pode tanto pronunciar o / R/ quanto apagá-lo.

O fenômeno tem sido investigado em relação a muitas variedades do $\mathrm{PB}$, como o estudo realizado por Oushiro e Mendes (2014) sobre o apagamento do /R/ em coda silábica no falar paulistano. A análise feita pelos autores conta com 118 entrevistas sociolinguísticas, e a estratificação social foi feita de acordo com sexo/gênero, faixa etária, nivel de escolaridade e região de residência do(a) informante. Foram analisados os fatores internos e externos condicionadores do apagamento ou da manutenção do /R/ em coda silábica. São eles: classe morfológica; posição da sílaba com R; contexto fônico precedente; contexto fônico seguinte; região de residência; sexo/gênero; indice socioeconômico; faixa etária; e estilo (conversação, depoimento, jornal e lista de palavras). Os autores constatam que, quando o morfema aparece no infinitivo verbal, seu apagamento é quase categórico, chegando a taxas de 97,4\% em conversação espontânea; no entanto, quando são analisados substantivos, adjetivos e advérbios, o apagamento é muito raro, com números que variam entre 3 e 9,7\%. Oushiro e Mendes (2014) também atestam que, quando se trata de conversação, as taxas chegam a 97\% de apagamento, ao passo que, no que tange à leitura de jornal, por exemplo, os índices de apagamento reduzem-se a apenas $4,9 \%$. Segundo a análise feita pelos autores, no primeiro grupo compilado (apagamento de morfema do infinitivo, por exemplo, em palavras como fazer ), as variáveis mais relevantes (OUSHIRO; MENDES, 2014) foram: contexto fônico precedente e nivel de escolaridade. No segundo grupo, denominado como "outras classes de palavras", as variáveis consideradas como mais relevantes pela análise feita pelos autores foram classe morfológica (conjunção/preposição, verbos finitos, advérbios/adjetivos, substantivos); posição da sílaba e região de residência. Nessa análise, os autores defendem que as classes que mais apresentam o processo são conjunção/preposição e verbo finito, representando taxas de $51,5 \%$ e $33,5 \%$, respectivamente. Quanto aos resultados que elencam somente substantivos (por exemplo, cerveja) e adjetivos (como em moderna), a posição da sílaba foi apontada como o grupo de fatores mais relevante e, em sequência, aparecem contexto fônico precedente; classe morfológica; e contexto fônico seguinte. ${ }^{5}$

Callou et al. (1998), em seu trabalho sobre a capital carioca, analisam o processo de enfraquecimento de / R/ em coda especificamente em contexto final de vocábulo. Os autores utilizamse da perspectiva da sociolinguística quantitativa para realizar sua pesquisa em tempo aparente e em tempo real de curta duração. Neste, são comparados dois períodos distintos de tempo, um estudo feito na década de 70 e outro realizado vinte anos depois. No falar carioca, o enfraquecimento de / R/ em coda em final de vocábulo segue o padrão apresentado, também, por Oushiro e Mendes (2014) em seu trabalho realizado sobre a capital paulista, com taxas de apagamento elevadas no Rio de Janeiro, como mostram Callou et al. (1998). Na primeira amostra, realizada

\footnotetext{
${ }^{5}$ Além do trabalho citado, correspondente ao apagamento de /R/ em coda silábica na cidade de São Paulo, destacamos a existência de outro trabalho feito pelos mesmos autores na capital paulista (OUSHIRO; MENDES, 2013 [2011]), referente às diferentes realizações fonéticas de / $\mathrm{R} /$ em coda.
} 
nos anos 70, a porcentagem de apagamento em verbos, como, por exemplo, comer, chegou a $73 \%$, apresentando uma elevação na nova amostra, feita nos anos 90 , que chega a $82 \%$. Em não verbos, como, por exemplo, forte, a taxa era de $32 \%$ nos anos 70 e se manteve na casa dos $32 \%$ na amostra dos anos $90 .{ }^{6}$

Chagas (2017) analisa o apagamento do rótico em fim de vocábulo também sobre o interior paulista. No entanto, o recorte de sua obra diferencia-se do presente estudo, como será exposto mais adiante. $\mathrm{O}$ autor seleciona quatro inquéritos do banco de dados IBORUNA, de duas informantes do sexo feminino e de dois informantes do sexo masculino. Todavia, após a análise da transcrição ortográfica, o autor alterna seu recorte para três mulheres, de mesmo grau de escolaridade e de faixas etárias distintas, a fim de compreender o fenômeno presente na fala de uma informante que fugiu da regularidade presente nas demais. No estudo do autor, o índice de apagamento em verbos é de 97\%, enquanto em não verbos é de 1,8\%. Dessa forma, o pesquisador afirma que "as formas verbais tendem a sofrer mais apagamentos dos róticos do que as formas não verbais. Esse resultado permite afirmar que a variedade rio-pretense segue o que já foi estudado em outras regiões do país" (CHAGAS, 2017, p. 608).

Vale ressaltar, mais uma vez, que o recorte utilizado pelo autor se diferencia do recorte presente nesta análise. Chagas (2017) considera apenas o contexto final de vocábulo, como em fazer, por exemplo, a fim de verificar a importância da fronteira prosódica para a realização do fenômeno de apagamento. Para isso, conduz uma análise em fonética acústica, por meio do software PRAAT (BOERSMA; WEENINK, 2019). O presente estudo, por sua vez, apresenta uma análise pautada na sociolinguística quantitativa, com a utilização do programa estatístico Goldvarb X (SANKOFF; TAGLIAMONTE; SMITH, 2005), considerando o contexto de / R/ não apenas em fim de vocábulo, como em escrever, como também em contexto medial, como em perdão.

O estudo de Galli (2015), sobre o apagamento de róticos em infinitivos na comunidade de fala de Assis Chateaubriand (PR), expande nosso leque de estudos realizados sobre o fenômeno. Galli (2015) analisou atitudes linguísticas de funcionários de uma empresa do município mencionado, a fim de constatar se os entrevistados utilizam a aplicação do /R/ em coda, ou se a rejeitam. A autora atestou que "na fala dos entrevistados não há a manutenção do / R/ em coda silábica final de verbos no infinitivo" (GALLI, 2015, p. 263). Nesse trabalho, a autora também explicita que as mulheres tendem a apagar mais o rótico no infinitivo, o que mostra que, aparentemente, a variante inovadora não sofre estigma social, tendo como pressuposto o fato de que, segundo a literatura sociolinguística, as mulheres tendem a realizar formas mais prestigiadas socialmente (LABOV, 2008 [1972]). Ademais, quando precedido pelas vogais /a/ (como, por exemplo, em publicar $)$, /e/ (fazer r e /i/ (ir r ), há um favorecimento maior ao processo, sendo a vogal /a/ a mais favorecedora.

Sabe-se que os trabalhos dos autores supracitados não são os únicos a discorrerem sobre o fenômeno do apagamento de / R/ em coda silábica em diferentes variedades do PB. Não obstante, fez-se necessária uma delimitação desta revisão da literatura, para que pudéssemos proceder à análise do fenômeno, valendo-nos, para tanto, dos procedimentos metodológicos apresentados na seção a seguir.

\section{Material e métodos}

Como apresentado, esta pesquisa utiliza-se dos estudos da Sociolinguística Quantitativa ou Teoria da Variação e Mudança Linguística (LABOV, 2008 [1972]) para a fundamentação teóricometodológica da pesquisa e análise dos dados coletados. Esses dados foram retirados do banco de dados IBORUNA (GONÇALVES, 2007), apresentado na subseção seguinte.

\footnotetext{
${ }^{6}$ Callou et al. (1998) apresentam três porcentagens em seu trabalho, no entanto, na segunda entrevista, não houve grande alteração percentual, o que fez com que mencionássemos apenas a primeira e a terceira porcentagens.
} 


\subsection{Corpus da pesquisa}

Como já citado, utilizamos, como corpus, oito inquéritos ${ }^{7}$ do banco de dados IBORUNA (GONÇALVES, 2007), resultado do Projeto ALIP (FAPESP - Proc. 03/08058-6). Esse banco de dados é formado por dois tipos de amostras: (i) Amostra

Censo, que conta com 152 entrevistas de informantes estratificados socialmente; e (ii) Amostra de Interação Dialógica, constituída por amostras de fala coletadas de forma secreta, em situações livres de interação social. Nesta pesquisa, utilizamos a primeira amostra, por ser aquela que controla os perfis sociais necessários para a averiguação da influência das variáveis independentes sexo/gênero (feminino ou masculino), escolaridade (primeiro ciclo do Ensino Fundamental ou Ensino Superior) e faixa etária (de 16 a 25 anos ou acima de 55 anos). Além desses grupos de fatores, são investigadas cinco variáveis linguísticas:

(i) Classe morfológica da palavra (nome ou verbo);

(ii) Posição da sílaba (medial ou final);

(iii) Contexto fônico precedente (dividido de acordo com as sete vogais tônicas orais do português: /a/, /E/, /e/, /i/, /O/,/o/, /u/);

(iv) Contexto fônico seguinte (pausa, consoante coronal, consoante dorsal, consoante labial, vogal /a/, /E/,/e/, /i/, /O/, /o/,/u/); e

(v) Tonicidade da sílaba (tônica ou átona).

A seção seguinte descreve mais detalhadamente as variáveis analisadas.

\subsection{Variáveis investigadas}

Como variável dependente, temos o apagamento de / $\mathrm{R} /$ em coda silábica na variedade do interior paulista. Já as variáveis independentes, elencadas na seção anterior, são mais detalhadamente explicadas a seguir.

A classe morfológica da palavra foi utilizada com a hipótese de que o processo de apagamento de / R/ em coda silábica ocorre na classe gramatical dos verbos, como sinalizam os exemplos vou andá $\varnothing$ e *primeiro andá $\varnothing$. Em nossa pesquisa, então, foram investigados os fatores nomes (englobando substantivos e adjetivos) e verbos.

A posição da sílaba dentro do vocábulo, como o nome pressupõe, trata da posição da sílaba dentro da palavra. Nesse grupo de fatores, foram subdividas as posições medial, como em marca, e final, como em ter. Atrelada ao grupo de fatores anterior, tínhamos, como hipótese, que a sílaba final favoreceria a aplicação do processo, visto que se trata do contexto de infinitivo verbal, como no exemplo já apresentado ter.

Quanto ao contexto fônico precedente, foram analisadas as sete vogais tônicas orais do português em contexto precedente ao /R/ em coda. São elas: /a, e, E, i, O, o, u/. A vogal /a/ está presente em vocábulos como usar, por exemplo. A vogal /e/ em vocábulos como fazer. A vogal /E/ em perto, por exemplo. Por sua vez, /i/ está representado em circuito e /O/ é representado por vocábulos como corta. Quanto à vogal /o/, podemos notar sua ocorrência em vocábulos como jornal. Por fim, /u/ aparece em ocorrências como curso, por exemplo.

O contexto fônico seguinte é representado por pausa, como em tiver..., ${ }^{9}$ pelas consoantes, classificadas em relação aos pontos de articulação, a saber: coronal, como em carne; dorsal, como em

\footnotetext{
${ }^{7}$ Dois sexos/gêneros x duas faixas etárias x duas escolaridades, totalizando oito entrevistas.

${ }^{8}$ Neste artigo, por razões de natureza tipográfica, as vogais médias-baixas anterior e posterior são representadas, respectivamente, como /E/ e /O/.

${ }^{9}$ As reticências representam a pausa.
} 
marcou; e labial, como em durmo, e por cada uma das sete vogais tônicas do PB. ${ }^{10}$ Por fim, consideramos a tonicidade da sílaba, dividida entre átona, por exemplo, em cursinho, ou tônica, por exemplo, em tomar. Faz-se necessária essa distinção a fim de apontar se sua presença em sílaba átona e/ou tônica favorece ou não o apagamento de / R/ em coda.

Em relação às variáveis extralinguísticas, o sexo/gênero foi considerado tendo em vista a disparidade entre homens e mulheres no contexto (socio)linguístico. As mulheres tendem a preservar a norma prestigiada devido à adequação social, à busca por respeito e igualdade ante ao mercado de trabalho e uma inserção em uma sociedade machista e opressora. "A diferenciação sexual não é, portanto, somente um produto de fatores físicos [...], mas sim, uma postura expressiva que é socialmente mais apropriada para um sexo do que para o outro" (LABOV, 2008 [1972], p. 348-349). Desse modo, por meio da investigação do sexo/gênero, podem-se obter indícios de estigma ou prestígio social em relação à determinada variante linguística.

A escolaridade é relevante para nossa pesquisa, pois, tendo acesso ao nível de escolarização dos informantes, podemos traçar eventuais fatos linguísticos característicos de uma alta ou baixa escolarização. Sendo assim, também pode apontar indícios de prestígio ou estigma social a determinada variante linguística. Por fim, a faixa etária é responsável por fornecer indícios do status da mudança linguística, ou seja, indica se há, na variedade estudada, um caso de variação estável ou de mudança em progresso, por meio de um estudo em tempo aparente, como apresentado no item 1.1.

\subsection{Passos metodológicos}

Para o levantamento dos dados a partir dos oito inquéritos selecionados do banco de dados IBORUNA, foram necessários seus arquivos de áudio e de transcrição ortográfica. Uma vez que não há qualidade suficiente para a análise acústica dos dados, procedeu-se à análise de oitiva para a observação da aplicação do fenômeno e codificação dos contextos linguísticos e extralinguísticos de cada ocorrência. A partir da utilização do programa estatístico Goldvarb X, ${ }^{11}$ procedeu-se à análise e à discussão dos dados, apresentadas a seguir.

\section{Análise e discussão dos dados}

Antes da apresentação da análise, deve-se salientar que, na primeira rodada dos dados, foram obtidos três nocautes, os dois primeiros referentes ao contexto fónico precedente, e o terceiro referente ao contexto fônico seguinte. ${ }^{12}$ Para resolver esses nocautes, optou-se pela manutenção da informação da altura das vogais como fator decisivo na análise. Dessa forma, foram amalgamadas, no contexto fônico precedente, a vogal média-baixa posterior $(\mathrm{O})$ à vogal média-baixa anterior $(\mathrm{E})$, como também a vogal alta anterior (i) à vogal alta posterior (u). No contexto fónico seguinte, foram amalgamadas a vogal média-baixa posterior $(\mathrm{O})$ e a vogal média-baixa anterior (E). Resolvidos os nocautes, a análise pôde prosseguir sem obstáculos.

A rodada dos dados mostrou ter sido obtida convergência ${ }^{13}$ na iteração 11 e apresentou os grupos de fatores significativos estatisticamente, a saber, em ordem decrescente:

\footnotetext{
${ }^{10}$ Nesse contexto, foram englobadas as vogais nasais a suas correspondentes orais.

11 "Um conjunto de programas computacionais de análise multivariada, especificamente estruturado para acomodar dados de variação sociolinguística” (GUY; ZILLES, 2007, p. 105).

12 Para o contexto fônico precedente, a vogal média baixa posterior $(\mathrm{O})$ apresentou 110 ocorrências e a vogal alta posterior (u) apresentou 54 ocorrências, todas com manutenção do / R/ em coda. Para o contexto fônico seguinte, a vogal média baixa posterior $(\mathrm{O})$ apresentou apenas uma ocorrência, e dela advém o apagamento do / R/.

13 A convergência, segundo Guy e Zilles (2007, p. 238), é obtida quando o programa pára de fazer ciclos “de ajustes nos valores dos pesos, procurando um resultado otimizado ('best fit') entre o modelo matemático e os dados observados".
} 
(i) Classe morfológica;

(ii) Posição da sílaba;

(iii) Contexto fônico precedente; e

(iv) Contexto fônico seguinte.

Pode-se perceber, de imediato, que as três variáveis sociais (sexo/gênero, escolaridade e faixa etária) foram descartadas pelo programa estatístico, o que demonstra que o processo analisado corresponde a um fenômeno, sobretudo, de natureza linguística. A exclusão das variáveis sociais sexo/gênero e escolaridade dão indícios de que a alternância de / $\mathrm{R} /$ em coda silábica, no interior paulista, consiste em um processo não estigmatizado socialmente. Esse resultado pode ser confirmado ou refutado por testes de avaliação das formas alternantes, o que é deixado para futuras pesquisas.

Já a exclusão da faixa etária, nesta amostra, demonstra que o fenômeno corresponde a um caso de variação estável, e não de mudança em progresso. Podemos afirmar que, assim como nas regiões do Rio de Janeiro (RJ) (CALLOU et al., 1998) e de São Paulo (SP) (OUSHIRO; MENDES, 2014), em São José do Rio Preto, estamos tratando de um caso de variação estável, uma vez que informantes dos diferentes grupos etários apresentam a aplicação do processo com frequências muito próximas, no grupo mais jovem correspondendo a 54,6\% e, no grupo mais velho, $50,1 \%$.

Ademais, deve-se destacar também o descarte da tonicidade da sílaba, que aponta a não interferência, para a aplicação ou não do apagamento, da natureza tônica ou átona da sílaba em que o /R/ está fonologicamente inserido, como em porta e importante, respectivamente. Na tabela seguinte (tabela 1), são apresentados os resultados gerais.

Tabela 1 - Apagamento e não apagamento de / R/ em coda silábica

\begin{tabular}{cccc}
\hline & Apagamento & Não apagamento & Total \\
\hline Ocorrências & 1254 & 1146 & 2400 \\
Frequências & $52,2 \%$ & $47,8 \%$ & $100 \%$ \\
\hline
\end{tabular}

Input: ${ }^{14} 0.232$

Significância: ${ }^{15} 0.010$

Fonte: Elaboração própria

Podemos perceber, de modo geral, taxas muito próximas $(52,2 \%)$ de apagamento e de manutenção $(47,8 \%)$ de / R/ em coda. Um exemplo de dado em que houve a supressão do rótico foi cozinháØ. Como vocábulo que mantém a pronúncia do / R/ em coda, podemos citar, por exemplo, o nome liquidificador, que não apresentou nenhuma ocorrência do fenômeno durante a análise.

Feita a exposição dos resultados gerais, passamos agora à descrição mais detalhada de cada um dos grupos de fatores linguísticos considerados relevantes para o fenômeno estudado.

\subsection{Análise e discussão dos dados referentes às variáveis linguísti- cas relevantes}

Em relação à classe morfológica da palavra, apontada como o grupo de fatores mais relevante, a tabela 2 expõe os índices de apagamento de /R/ em verbos e nomes.

\footnotetext{
14 "O imput representa o nível geral de uso de determinado valor da variável dependente" (GUY; ZILLES, 2007, p. 238, grifo dos autores).

${ }^{15}$ Significância "é essencialmente um modo de estimar a probabilidade de se obter determinada distribuição de dados pressupondo certas características [...]” (GUY; ZILLES, 2007, p. 85).
} 
Tabela 2 - Índices de apagamento de / R/ em relação à classe morfológica da palavra

\begin{tabular}{lcccc}
\hline Fatores & $\begin{array}{c}\text { Frequências de } \\
\text { apagamento }\end{array}$ & Ocorrências gerais & $\begin{array}{c}\text { Ocorrências de } \\
\text { apagamento }\end{array}$ & PR \\
\hline Verbos & $91,6 \%$ & 1350 & 1237 & 0.922 \\
Nomes & $1,6 \%$ & 1050 & 16 & 0.040 \\
\hline Total & $52,2 \%$ & 2400 & 1254 & \\
\hline
\end{tabular}

Input: 0.232

Significância: 0.010

Fonte: Elaboração própria

Fica evidente, pelos percentuais e pesos relativos (PRs) elencados, que as ocorrências do processo são díspares nas diferentes classes de palavras. Em relação às incidências de apagamento de /R/ em verbos, como, por exemplo, ficá $\varnothing$, a taxa de apagamento foi de 91,6\%, com PR 0.922, enquanto em não verbos, como em conversa, a taxa de apagamento foi de apenas 1,6\% (PR 0.040).

Esse resultado vai ao encontro do que outros estudos do mesmo fenômeno apontam em diferentes variedades do PB. Em relação ao interior paulista, por exemplo, confirma os resultados de Chagas (2017), que verificou $97 \%$ de apagamento de /R/ em verbos e 1,8\% em não-verbos. No que tange ao município de São Paulo, a pesquisa feita por Oushiro e Mendes (2014) elucida que os índices de apagamento de / R/ em verbos foram altos, chegando a 97\% em conversação, por exemplo, ao passo que, em outras classes de palavras, houve uma redução significativa do apagamento do rótico, com índice de apenas $12 \%$ em advérbios, por exemplo. Por meio da tabela 3 , apresentamos os resultados referentes ao apagamento de acordo com a posição da sílaba no vocábulo, selecionada como a segunda mais relevante.

Tabela 3 - Índices de apagamento de / R/ em relação à posição da sílaba

\begin{tabular}{ccccc}
\hline Fatores & $\begin{array}{c}\text { Frequências de } \\
\text { apagamento }\end{array}$ & Ocorrências gerais & $\begin{array}{c}\text { Ocorrências de } \\
\text { apagamento }\end{array}$ & PR \\
\hline Medial & $0,7 \%$ & 919 & 6 & 0.018 \\
Final & $84,3 \%$ & 1481 & 1248 & 0.924 \\
\hline Total & $52,2 \%$ & 2400 & 1254 & \\
\hline
\end{tabular}

Input: 0.232

Significância: 0.010

Fonte: Elaboração própria

A tabela 3 mostra que, em meio de vocábulo, como, por exemplo, em parte, houve uma taxa baixa de apagamento de $/ \mathrm{R} / \mathrm{em}$ coda, correspondente a apenas $0,7 \%$ do total de dados (PR 0.018), enquanto que, em fim de vocábulo, como em fazể $\varnothing$, os índices chegam a 84,3\% (PR 0.924). Os resultados desta pesquisa apontam que, quando o segmento se localiza em meio de vocábulo, há tendência de desfavorecimento do apagamento de / R/ em coda. Em contrapartida, quando a ocorrência é em fim de vocábulo, o apagamento é altamente favorecido.

Considerando o que foi apresentado até o momento, verificamos que, quando estamos tratando de verbos e quando o /R/ aparece em posição final de vocábulo, contexto de infinitivo verbal, o apagamento do segmento é altamente favorecido. Isso confirmou a hipótese inicial da presente pesquisa: de que o processo ocorreria majoritariamente em verbos.

Como observado na tabela 3, houve seis ocorrências de apagamento de / R/ em posição medial. Quando verificados os dados, observamos que todas as ocorrências ocorrem em nomes, com exceção de refoØçando. Em um dos vocábulos, supeØvisor, podemos argumentar que se trata, na verdade, de duas palavras fonológicas, dada a presença de dois acentos fonológicos, e, assim, ambos os /R/ ocupam a posição final do vocábulo fonológico ao qual pertencem. Dos outros vocábulos, nota-se que, em três (iØmão, enfeØmeira e noØmal), o /R/ é precedido por consoante labial, contexto favorecedor do apagamento, como apresentaremos mais adiante.

Os resultados estatísticos apresentados evidenciam também que há um grande favorecimento da manutenção de / R/ em contexto medial e em não verbos, como em cartão. Ainda as- 
sim, podemos notar casos de apagamento em contexto final em nomes, como em jogadô $\varnothing$, colhé $\varnothing$, celulá $\varnothing$, lugá $\varnothing$ e governadô $\varnothing$, por exemplo.

precedente.

A tabela 4, a seguir, apresenta a aplicação do fenômeno em relação ao contexto fônico

(ISSN 2238-8060) Tabela 4 - Índices de apagamento de / R/ em relação ao contexto fônico precedente

\begin{tabular}{|c|c|c|c|c|}
\hline Fatores & $\begin{array}{c}\text { Frequências de } \\
\text { apagamento }\end{array}$ & Ocorrências gerais & $\begin{array}{c}\text { Ocorrências de } \\
\text { apagamento }\end{array}$ & PR \\
\hline $\begin{array}{l}\text { Vogais altas anterior } \\
\text { e posterior }\end{array}$ & $49,8 \%$ & 243 & 121 & 0.444 \\
\hline $\begin{array}{l}\text { Vogal média-alta } \\
\text { anterior }\end{array}$ & $56,9 \%$ & 714 & 406 & 0.548 \\
\hline $\begin{array}{l}\text { Vogal média-alta } \\
\text { posterior }\end{array}$ & $4,6 \%$ & 284 & 13 & 0.064 \\
\hline $\begin{array}{l}\text { Vogais médias- } \\
\text { baixas anterior e } \\
\text { posterior }\end{array}$ & $33 \%$ & 171 & 57 & 0.668 \\
\hline Vogal baixa central & $66,5 \%$ & 988 & 657 & 0.638 \\
\hline Total & $52,2 \%$ & 2400 & 1254 & \\
\hline
\end{tabular}

Input: 0.232

Significância: 0.010

Fonte: Elaboração própria

As vogais médias-baixas anterior e posterior, como, por exemplo, em melhó $\varnothing$ e estivé $\varnothing$, e a vogal baixa central, como estudá $\varnothing$, são as vogais com maiores índices de favorecimento do processo de apagamento de / R/ em coda silábica: PRs 0.668 e 0.638 , respectivamente. O contrário ocorre quando estamos tratando da vogal média-alta posterior /o/, como em ventilador, que é altamente desfavorecedora do processo (PR 0.064). As vogais altas (PR 0.444), como em emitir e turma, e a vogal média-alta anterior (PR 0.548), como fazer, apresentam posições relativamente neutras.

Segundo a análise elencada na fundamentação teórica deste trabalho, Galli (2015) afirma que o apagamento de /R/ é favorecido pela vogal baixa central em Assis Chateaubriand (PR). Percebe-se que, na comunidade de fala do interior paulista, também há forte tendência ao apagamento de /R/ quando precedido da vogal baixa central, contexto de verbos de primeira conjugação. Ademais, o favorecimento à realização do processo pode ser consequência de a maioria dos verbos em português ter terminação -ar, assim, sobrepondo-se aos demais.

Dados esses resultados e o fato de, como já apresentado no início desta seção, não ter havido ocorrência de apagamento nas 110 ocorrências de /R/ precedido por vogal média baixa posterior /O/ nem nas 54 ocorrências precedidas por vogal alta posterior /u/, observa-se maior atuação das vogais anteriores e central em prol da aplicação do fenômeno. De modo geral, correspondem às três conjugações da língua portuguesa, o que nos remete aos resultados da tabela 1 , que apontam a classe gramatical do verbo (predominantemente na forma infinitiva) como a grande favorecedora da aplicação do fenômeno. A tabela a seguir apresenta os dados referentes ao contexto fônico seguinte. 
Tabela 5 - Índices de apagamento de / R/ em relação ao contexto fônico seguinte

\begin{tabular}{lcccc}
\hline \multicolumn{1}{c}{ Fatores } & $\begin{array}{c}\text { Frequências de } \\
\text { apagamento }\end{array}$ & $\begin{array}{c}\text { Ocorrências } \\
\text { gerais }\end{array}$ & $\begin{array}{c}\text { Ocorrências de } \\
\text { apagamento }\end{array}$ & PR \\
\hline Vogal alta posterior & $97 \%$ & 67 & 65 & 0.903 \\
Vogal média-alta anterior & $88,9 \%$ & 18 & 16 & 0.776 \\
Consoante labial & $38,3 \%$ & 405 & 155 & 0.731 \\
Vogal baixa central & $94,9 \%$ & 138 & 131 & 0.637 \\
Vogais médias-baixas & $93,2 \%$ & 59 & 55 & 0.559 \\
anterior e posterior & & & & \\
Consoante coronal & $24,7 \%$ & 815 & 201 & 0.501 \\
Consoante dorsal & $47,1 \%$ & 189 & 89 & 0.413 \\
Vogal alta anterior & $49,8 \%$ & 243 & 121 & 0.413 \\
Vogal média-alta posterior & $4,6 \%$ & 284 & 13 & 0.468 \\
Pausa & $74,3 \%$ & 637 & 473 & 0.315 \\
\hline Total & $52,2 \%$ & 2400 & 1254 & \\
\hline
\end{tabular}

Input: 0.232

Significância: 0.010

Fonte: Elaboração própria

Nota-se que o apagamento de / R/ em coda é quase categórico quando sucedido da vogal alta posterior (97\%, PR 0.903), como, por exemplo, abrir um. Também há tendência favorecedora quando estamos tratando da vogal média-alta anterior (PR 0.776), como em resolveØ entre; vogal baixa central (PR 0.637), por exemplo entendeØ as; vogal média-baixa anterior e posterior (PR 0.559), como em realizaØ essas; e consoante labial (PR 0.731), como em aprendeØ matemática.

Os contextos fônicos seguintes tidos como desfavorecedores do processo foram a consoante com ponto de articulação dorsal (PR 0.413), como em porco, a vogal média-alta posterior (PR 0.468) e, principalmente, a pausa (PR 0.315). A consoante coronal, como em surdo, apresenta-se como neutra (PR 0.501).

Para resultados mais precisos em relação ao contexto fônico seguinte, julgamos ser necessário seu cruzamento com a posição da sílaba no vocábulo. A partir desse cruzamento, esperava-se que o apagamento do /R/ final fosse mais frequente quando seguido por consoante e desfavorecido quando seguido por vogal, tendo em vista o fato de o rótico na posição intervocálica ser produzido como tepe, como em arara, o que favoreceria sua manutenção.

Realizado esse cruzamento, o que constatamos, na verdade, é a grande relevância da posição da sílaba no vocábulo, que apresenta altas porcentagens de aplicação do fenômeno quando se trata de / R/ final, independentemente do segmento fônico seguinte. Fica minimizada, portanto, a relevância do contexto fônico seguinte.

Em suma, os resultados desta pesquisa apontam que os fatores linguísticos são muito mais significativos do que os extralinguísticos para o apagamento do / R/ em coda silábica no interior paulista. Notamos que a estrutura presente por trás da aplicação do processo é de caráter morfofonológico, atuando, sobretudo, no morfema de infinitivo verbal, como em ficaØ, seØ e surgi

\section{Considerações finais}

Por meio desta pesquisa, constatamos que o apagamento de /R/ em coda no interior paulista consiste em um processo de natureza morfofonológica, presente principalmente no contexto de morfema de infinitivo verbal. O resultado confirma a hipótese inicial de que esse fenômeno ocorreria, sobretudo, em verbos. Além disso, vai ao encontro de estudos e considerações já realizados sobre esse fenômeno em outras variedades do PB.

Constatamos indícios de que, quando precedido das vogais anteriores e central, há uma tendência maior ao apagamento de / $\mathrm{R} /$ em coda, o que nos remete às três conjugações verbais da língua portuguesa. Em relação ao contexto fônico seguinte, apontado como relevante pelo programa estatístico, sua importância é minimizada quando efetuado o cruzamento com a posição da 
sílaba. Finalmente, a pesquisa ora apresentada preenche uma lacuna quanto ao Português falado no interior paulista, e, de forma mais abrangente, ao PB, uma vez que contribui para a descrição da variação fonético-fonológica desta língua tão plural.

\section{Referências}

BAGNO, M. Preconceito linguístico. 56. ed. São Paulo: Parábola, 2015.

BOERSMA, P.; WEENINK, D. (2019). Praat. Doing Phonetics by Computer [Computer program]. Version 6.1.01. Disponível em: http://www.praat.org/. Acesso em: 16/08/2019.

CALLOU, D. et al. Apagamento do R Final no Dialeto Carioca: um Estudo em Tempo Aparente e em Tempo Real. Delta: Documentação de Estudos em Linguística Teórica e Aplicada, [s.l.], v. 14, p. 61-72, 1998.

CARMO, M. C. As vogais médias pretônicas dos verbos na fala culta do interior paulista. 2009. 119 f. Dissertação (Mestrado em Estudos Linguísticos) - Instituto de Biociências, Letras e Ciências Exatas, Universidade Estadual Paulista, São José do Rio Preto, 2009.

CARMO, M. C. As vogais médias pretônicas na variedade do interior paulista. 2013. 249 f. Tese (Doutorado em Estudos Linguísticos) - Instituto de Biociências, Letras e Ciências Exatas, Universidade Estadual Paulista, São José do Rio Preto, 2013.

CARMO, M. C. As vogais médias pretônicas no noroeste paulista: comparação com outras variedades do Português Brasileiro. Revista Estudos Linguísticos. v. 43, n. 1, p. 33-47, 2014.

CARMO, M. C. Alçamento vocálico das vogais médias pretônicas iniciais na variedade do noroeste paulista. Revista Estudos Linguísticos. v. 48, n. 2, p. 800-821, jul. 2019.

CARMO, M. C.; TENANI, L. E. As vogais médias pretônicas na variedade do noroeste paulista. Alfa: Revista de Linguística. v. 57, n. 2, p. 607-637, 2013.

CHAGAS, V. D. O comportamento das fronteiras prosódicas no apagamento rótico em posição de coda final de palavras. Mosaico. São José do Rio Preto, v. 16, n. 1, p. 597-620, 2017.

GALLI, M. C. Um estudo de caso sobre o apagamento dos róticos no infinitivo. Travessia, Cascavel, v. 9, n. 01, p. 254-268, 2015.

GONÇALVES, S. C. L. Banco de dados Iboruna: amostras eletrônicas do português falado no interior paulista. 2007. Disponível em: http://www.alip.ibilce.unesp.br/iboruna. Acesso em: 16/08/2019.

GUY, G. R.; ZILLES, A. M. S. Sociolinguística quantitativa: instrumental de análise. São Paulo: Parábola, 2007.

LABOV, W. Padrões sociolinguísticos. Tradução de Marcos Bagno, Maria Marta Scherre, Caroline Rodrigues Cardoso. São Paulo: Parábola, 2008 [1972].

OUSHIRO, L.; MENDES, R. B. A pronúncia do (-R) em coda silábica no português paulistano. Revista do GEL. São Paulo. V.8. n. 2. p.66-95. 2013 [2011].

OUSHIRO, L.; MENDES, R. B. O apagamento de (-r) em coda nos limites da variação. Veredas. Juiz de Fora (MG). v.18. n. 2. P. 251-266. 2014.

PAIVA, M. C.; DUARTE, M. E. L. Mudança Linguística: observações no tempo real. In: MOLLICA, M. C.; BRAGA, M. L. (Org.). Introdução à sociolinguística: o tratamento da variação. 4. ed. São Paulo: Contexto. p. 179-190. 2015.

SANKOFF, D.; TAGLIAMONTE, S. A.; SMITH, E. Goldvarb X: a Variable Rule Application for Macintosh and Windows. Department of Linguistics, University of Toronto, 2005. Disponível em: http://individual.utoronto.ca/tagliamonte/goldvarb.html. Acesso em: 01/06/2019.

SILVA, T. C. Dicionário de Fonética e Fonologia. São Paulo: Contexto, 2011.

SILVEIRA, A. A. M. As vogais pretônicas na fala culta do noroeste paulista. 2008. 143 f. Dissertação (Mestrado em Estudos Linguísticos) - Instituto de Biociências, Letras e Ciências Exatas, Universidade Estadual Paulista, São José do Rio Preto, 2008.

TARALLO, F. A pesquisa sociolinguística. 7. ed. São Paulo: Ática, 2003.

https://periodicos.unifap.br/index.php/letras

Macapá, v. 9, n. 3, $2^{\circ}$ sem., 2019 
Enviado em: 15/06/2019

Aceito em: 13/09/2019

Escreve

(ISSN 2238-8060) 